$\begin{array}{ll} & \text { Etnográfica } \\ \text { etnográfica } & \text { Revista do Centro em Rede de Investigação em }\end{array}$

Antropologia

vol. $18(3) \mid 2014$

Vol. $18(3)$

\title{
Habilitar corpos e pessoas: práticas e conhecimentos de vidas com cegueira
}

Enabling bodies and individuals: practical knowledge of life with blindness

\section{Olivia von der Weid}

\section{(2) OpenEdition}

\section{Journals}

\section{Edição electrónica}

URL: https://journals.openedition.org/etnografica/3803

DOI: 10.4000/etnografica.3803

ISSN: 2182-2891

\section{Editora}

Centro em Rede de Investigação em Antropologia

\section{Edição impressa}

Data de publição: 1 outubro 2014

Paginação: 499-520

ISSN: 0873-6561

\section{Refêrencia eletrónica}

Olivia von der Weid, «Habilitar corpos e pessoas: práticas e conhecimentos de vidas com cequeira», Etnográfica [Online], vol. 18 (3) | 2014, posto online no dia 09 outubro 2014, consultado o 11 fevereiro 2022. URL: http://journals.openedition.org/etnografica/3803 ; DOl: https://doi.org/10.4000/ etnografica.3803

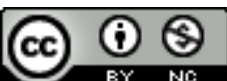

Etnográfica is licensed under a Creative Commons Attribution-NonCommercial 4.0 International License. 


\section{Habilitar corpos e pessoas: práticas e conhecimentos de vidas com cegueira}

\section{Olivia von der Weid}

As reflexões aqui elaboradas tiveram o intuito de seguir práticas nas quais pessoas, corpos, sentidos, objetos, manuais, ambiente, dispositivos e estratégias são incorporados, treinados ou desenvolvidos para se viver com a cegueira, tendo como base a vida cotidiana. Resultam de um trabalho etnográfico que procurou acompanhar os conhecimentos práticos desenvolvidos por profissionais e pacientes em um centro de reabilitação, mas também por pessoas cegas nas suas práticas da vida diária. Com a falta ou a perda da visão, os outros sentidos e o corpo inteiro se colocam como mecanismos de apreensão do mundo, do ambiente, das pessoas. Pretende-se abordar a percepção de mundo de pessoas cegas a partir das relações que estabelecem por meio de seus corpos. Com ênfase nas práticas, busca-se uma aproximação de como esses corpos interagem com o ambiente e o tipo de vivência e conhecimento de mundo que se produz. A proposta é entender como se dá a (re)organização corporal a partir da ausência ou da perda da visão e quais habilidades, técnicas e estratégias são criadas ou desenvolvidas.

PALAVRAS-CHAVE: cegueira, reabilitação, práticas, corpo, materiais.

Enabling bodies and individuals: practical knowledge of life with blindness - The reflections elaborated here have the intention to follow practices in which people, bodies, senses, objects, books, environment, devices and strategies are incorporated, developed or trained to live with blindness, based on everyday life. They are a result of an ethnographic study that intended to go along with the practical knowledge developed by professionals and patients in a rehabilitation center, but also by blind people in their daily life practices. With the lack or loss of vision, other senses and the whole body arise as mechanisms to apprehend the world, the environment, the people. The intention is to approach the perception of the world of blind people from the relationships they establish through their bodies. With an emphasis on practices, we seek to approach how these bodies interact with the environment and what kind of experience, skills, techniques and knowledge of the world is produced in this process.

KEYWORDS: blindness, rehabilitation, practices, body, materials.

VON DER WEID, Olivia (oliviaweid@gmail.com) - Programa de Pós-Graduação em Sociologia e Antropologia (PPGSA), Universidade Federal do Rio de Janeiro (UFRJ), Brasil. 


\section{INTRODUÇÃO}

Com a falta ou a perda da visão, os outros sentidos e o corpo inteiro se colocam como mecanismos de apreensão do mundo, do ambiente, das pessoas. Pretende-se neste artigo abordar a percepção de mundo de pessoas cegas a partir das relações que estabelecem por meio de seus corpos. Com ênfase nas práticas cotidianas, busca-se uma aproximação de como esses corpos interagem com o ambiente e o tipo de vivência e conhecimento de mundo que se produz. A proposta é entender como se dá a (re)organização corporal a partir da ausência ou da perda da visão e quais habilidades, práticas e estratégias são criadas ou desenvolvidas.

Para falar sobre as percepções de mundo de pessoas cegas é preciso passar pela mediação de instituições no desenvolvimento desse corpo, seja para quem nasce ou quem se torna. Procura-se enfatizar a dimensão didática e funcional de ser ou tornar-se cego, a partir de um acompanhamento de como esse processo acontece no dia a dia, na interação entre profissionais e pessoas atendidas em um programa de reabilitação.

Considerar o trabalho da fabricação implica em mudar a atenção para o que nos faz agir (Latour 1996). O exame das atividades cotidianas da reabilitação e das práticas diárias de pessoas cegas faz emergir uma série de mediadores entre ver e não ver (também presentes na escola nas técnicas de ensino especiais, nos materiais, programas de estimulação precoce, etc.). Acompanhar esses processos significa considerar que os gestos aparentemente mais insignificantes contribuem para a construção social dos fatos - corpo cego, bengala, mobilidade, (in)dependência - e coloca em evidência o caráter idiossincrático, local, heterogêneo e contextual das práticas de cegueira.

Nas instituições e nos programas de (re)habilitação para pessoas cegas encontramos uma série de práticas que têm como finalidade ajudar o indivíduo nesse processo de desenvolvimento de novas formas de fazer coisas, novos princípios organizadores e geradores de atividades. A análise resulta de um trabalho etnográfico que procurou acompanhar os conhecimentos práticos desenvolvidos por profissionais e pacientes em um centro de reabilitação, mas também por pessoas cegas nas suas atividades cotidianas. Para tanto, concluí o curso de 40 horas de formação como técnica de Orientação e Mobilidade pelo Instituto Benjamin Constant (IBC). Acompanhei pelo período de quatro meses os atendimentos básicos oferecidos pelo setor de reabilitação do Instituto - Habilidades Básicas, Braille, Atividades da Vida Diária (AVD) e Orientação e Mobilidade (OM). Foram realizadas entrevistas com profissionais e com pessoas cegas a respeito de suas práticas cotidianas, além de ter visitado dois apartamentos onde moram duas das pessoas entrevistadas, para melhor compreender como funcionam as suas estratégias de organização do ambiente doméstico, objetos, utensílios, alimentos, roupas, aparelhos, entre outros, em suas vidas diárias. 
Neste artigo procuro adotar a sugestão de Bourdieu (2011) de retornar às práticas para compreender o social, focando nas atividades reais como tais, nas relações práticas dos agentes com o mundo. Descrevendo ações e atividades observadas em atendimentos da reabilitação ou as formas de fazer de pessoas cegas nas suas relações cotidianas, busca-se o encontro com esse senso prático nas próprias situações em que está localizado, já que, como lembra Bourdieu, a lógica prática não funciona sem lastro.

Com essa leitura, pretende-se escapar da distinção entre sujeito e objeto, ativo e passivo, indo à busca da pista de Latour (1999) de perseguir a cadeia de mediadores, a proliferação de objetos, propriedades, seres, receios, técnicas que nos levam a fazer coisas aos outros. Considerar a natureza daquilo que nos faz ser. Não é mais uma questão de opor ligamento ou desligamento, mas, ao invés disso, de questionar quais são os laços favoráveis ou desfavoráveis. Ao interrogar sobre esta distinção deslocamos nossa atenção para os próprios vínculos. Para Latour só há uma forma de decidir a qualidade desses vínculos investigar do que consistem, o que fazem, como se é afetado por eles.

\section{A ENTRADA NA REABILITAÇÃO}

O Instituto Benjamin Constant é um centro de referência nacional para questões da área de deficiência visual no Brasil. Dentre as atividades que acontecem no IBC encontram-se: escola com atendimento em estimulação precoce, educação infantil e ensino fundamental, capacitação de profissionais de diversas áreas na temática da deficiência visual, assessoria a escolas e instituições, realização de consultas e cirurgias oftalmológicas, reabilitação de jovens e adultos, desenvolvimento de programas especiais, além da produção de material especializado em braille e em relevo (mapas, gráficos, etc.) e publicações científicas.

A divisão de reabilitação do IBC foi criada para atender a demanda de pessoas que se tornam cegas na idade adulta e está ligada ao Departamento de Estudos e Pesquisas Médicas e de Reabilitação. Além de reabilitar, tem o objetivo da preparação para o trabalho e encaminhamento profissional, que nos remete à preocupação dos primeiros centros de reabilitação, a capacidade funcional e desempenho ocupacional.

A proposta do atendimento da reabilitação é que o programa seja planejado individualmente. $\mathrm{Na}$ conversa com a psicóloga - a partir de perguntas como: "há quanto tempo ficou cego?", "como?", "o que está acontecendo?", "porque procurou o IBC agora?", "quem indicou?", "quais são as maiores dificuldades que encontra no dia a dia e que atribui à deficiência visual?" -, procura-se montar um plano de reabilitação que satisfaça as necessidades da pessoa atendida e que a motive. Posteriormente, em alguns atendimentos, também são montados planos de acordo com as atividades de interesse específico do reabilitando. 
O ciclo básico da reabilitação inclui cinco atendimentos: Habilidades Básicas, Atividades da Vida Diária, Orientação e Mobilidade, Braille e Escrita Cursiva (este último sem professor na ocasião). Além destes atendimentos, o centro de reabilitação também oferece oficinas, que em alguns casos são ministradas por voluntários - informática, artesanato, cestaria/jornal, violão, cerâmica, afinação de piano, piano. Há também um curso de alfabetização de jovens e adultos, o Núcleo de Capacitação e Empregabilidade (Nucape), que atua em parcerias com instituições como o Senac e o Instituto Empreender, e um programa específico de atendimento à Surdocegueira.

Apesar de não ter um tempo de duração formalmente determinado para a reabilitação, informalmente costuma durar de três a quatro anos. A frequência aos atendimentos é de duas vezes por semana (segunda e quarta-feira, ou terça e quinta-feira), turno da manhã ou da tarde. Para os que não podem frequentar duas vezes, existe a opção de ir às sextas-feiras. Reconhecendo o papel da instituição enquanto local de convívio, encontro e sociabilidade, criou-se o grupo de convivência, onde são oferecidas, às sextas-feiras, oficinas para reabilitados que ainda mantêm o vínculo com a instituição, em geral ministradas por voluntários. A partir da entrevista inicial com a psicóloga, o reabilitando monta o seu horário e começa a frequentar os atendimentos que escolheu, de acordo com suas necessidades.

\section{O estímulo aos outros sentidos}

Prestar atenção no ambiente com o corpo. Aprender a discernir lugar fechado de lugar aberto pelo som ao redor e pela temperatura. Saber se está passando em frente a uma farmácia, uma padaria ou um posto de gasolina pelo cheiro característico desses estabelecimentos. As terapeutas ocupacionais com quem conversei, que realizam atendimentos de Orientação e Mobilidade e Atividades da Vida Diária, observam que uma das primeiras transformações na pessoa que fica cega é que seus outros sentidos ficam "aguçados". ${ }^{1}$ Essa sensibilidade maior derivaria de uma reação "natural" do corpo, que passa a recorrer ao que tem - os outros sentidos - para controlar o ambiente. A sensibilidade aumentada dos outros sentidos, a princípio um mecanismo de sobrevivência, deve ser estimulada e incentivada na pessoa cega, ela deve ser treinada a utilizá-la nas tarefas cotidianas. A partir desse treinamento dos sentidos é que os sinais significativos do entorno se tornam guias para a ação.

"A pessoa quando fica cega passa a recorrer mais ao ouvido e desenvolve uma sensibilidade. Antigamente pessoas cegas eram queimadas porque eram

l Como forma de abreviação, passarei a utilizar a abreviatura TO para me referir ao profissional de Terapia Ocupacional, assim como AVD para Atividades da Vida Diária e OM para Orientação e Mobilidade. 
mais sensitivas, achavam que era guru ou bruxa. Mas hoje a gente sabe que quando perde a visão, é uma questão de sobrevivência, recorre aos sentidos remanescentes. O primeiro é o ouvido, depois a pele, que se estende pelo corpo todo, mas também os pés, as mãos. Memória cinestésica também. Fica tudo mais aguçado, a pele fica mais sensível. Tem alguns que quando você toca, a pessoa já treme. O corpo se adapta à perda antes mesmo de o cérebro aceitar. $\mathrm{O}$ corpo humano se adapta muito rápido. Aí a gente tem que abrir a mente dele para aquela nova condição de vida. Falar para observarem o corpo, perceberem o que sentem, estimular o ouvido. Alguns têm medo do barulho porque levam susto com o ouvido que já está se adaptando" [TO do Instituto Benjamin Constant].

A medida para as coisas passa a não ser mais a mesma medida visual de antes, o mundo não se parece mais com o que se parecia antes. Mas esse mesmo mundo novo, num primeiro momento caótico, assustador, pode ser percebido, controlado, manipulado, organizado, por meio de indícios - táteis, sonoros, de temperatura, de movimento, etc. - significativos. É uma questão de aprender a ler sinais - aprender a reparar neles, a senti-los, a escutá-los.

“Já que você não está vendo... ó, eu vou fechar os olhos também. E aí, o que você está percebendo do ambiente? O que o ambiente está te dizendo? Tem um vento passando à minha direita, um perfume que passou à minha esquerda, uma bengala que passou andando lá longe... Tem uma folha de planta passando pelo meu braço... O quê que o ambiente está te dizendo? O que está acontecendo ao seu redor através dos outros sentidos? Isso é superimportante. Todos os sentidos, fora a visão, eles são aguçados na maioria das vezes. Nós como TO incentivamos muito isso, a percepção.”

Para Varela (2003), costumamos operar em uma espécie de imediatismo em relação a uma dada situação: o mundo em que vivemos está tão pronto e à mão que absolutamente não deliberamos sobre o que ele é e de que forma o habitamos. Apresentamos uma prontidão para ação adequada para cada situação específica vivida. Na abordagem "enativa” proposta pelo autor, a cognição depende dos tipos de experiência que advêm do fato de se possuir um corpo dotado de diversas capacidades sensório-motoras. Essas capacidades sensório-motoras individuais estão elas próprias embutidas em um contexto biológico e cultural mais abrangente. Maneiras novas de se comportar e as transições ou pontuações entre elas correspondem, para o autor, a microcolapsos que sofremos constantemente. Pessoas que ficam cegas precisam redescobrir, reaprender, reinventar tipos de interações direcionadas perceptivamente a partir de uma modificação significativa na estrutura sensório-motora de seus corpos. Pode-se pensar nesse processo como sendo de modificação/criação/ampliação 
das suas formas básicas de atividades e de interações sensório-motoras, de aquisição de um novo habitus corporal, novos esquemas de percepção e apreciação (Bourdieu 2011).

No caso de pessoas que nascem cegas não é tanto um processo de tradução - a forma como fazia antes e a forma como fará agora as mesmas coisas -, mas um trabalho de treinamento e desenvolvimento de formas sensório-motoras próprias para realizar tarefas algumas vezes criadas por outros. ${ }^{2}$

O treinamento dos sentidos na reabilitação se dá por um processo de educação da atenção, no sentido dado por Gibson (1979), durante a realização de atividades práticas. Não se trata de transmitir informações sobre como uma pessoa que fica cega deve passar a fazer essa ou aquela coisa, mas de efetivamente guiar sua ação para que, por meio da prática, do movimento do fazer, ela redescubra suas próprias formas de perceber o mundo e de realizar coisas.

Falamos de um senso prático que se desenvolve por um processo de aquisição como simulação, de mimesis (ou mimetismo) prático, como indica Bourdieu (2011). Para o autor, o senso prático - linguagem do tato, da habilidade, da delicadeza, da destreza ou do saber fazer, entre tantos outros nomes possíveis está fundamentalmente relacionado à ação em uma situação determinada. Esse parece ser um princípio que orienta ou estrutura todo processo de (re)habilitação de uma pessoa cega: os atendimentos se organizam essencialmente em torno de situações práticas, de ações orientadas, de disposições em atos. A lógica prática de que nos fala Bourdieu e que pode ser relacionada ao fazer proposto aos reabilitandos nos atendimentos está presa por aquilo de que se trata, totalmente presente no presente e nas funções práticas que ali se descobrem na forma de potencialidades objetivas.

O trabalho da reabilitação se aproxima ao da estimulação precoce em dois pontos principais: o foco no estímulo aos outros sentidos - prestar atenção com o corpo todo - e a mediação, nesse caso não exatamente de um professor, mas de um profissional da área de terapia ocupacional, psicomotricidade, fisioterapia, para o aprendizado da ação - do fazer, se movimentar, criar.

"A gente aqui enfatiza o quê? Os outros sentidos. Na pessoa cega ela precisa, quanto mais ela desenvolver a audição, o tato, a coisa motora, o corpo no espaço... Desde a estimulação precoce. É a piscina de bola, é a criança sentir as coisas. Esses outros sentidos são muito estimulados, esse é o nosso trabalho aqui. É o que a gente mais... em tudo. Então eu acho que é isso, é estimular os outros sentidos. Aí cada um vai por um caminho, é a questão da individualidade" [psicóloga do IBC].

2 Certas práticas cotidianas, como cortar alimentos como a carne, por exemplo, no prato junto com outros tipos de alimento, são tarefas que contam com a visualidade para sua execução e se tornam reconhecidamente penosas de serem executadas por quem não está vendo. 
Em muitos momentos, em entrevistas com profissionais ou com as próprias pessoas cegas, se enfatiza a diferença, a particularidade de cada um nesse processo de ser ou tornar-se cego. "Não tem receita de bolo". Estar atento especialmente com a audição, por exemplo, é algo que as pessoas cegas precisam constantemente fazer para perceber ou controlar o ambiente, mas não significa que toda pessoa cega desenvolve uma capacidade extraordinária para discriminar vozes, ou uma aptidão natural para virar músico. Dora, uma das entrevistadas, fala sobre essa questão:

"As pessoas dizem que as pessoas cegas ouvem melhor, eu não ouço melhor. Muito pelo contrário, eu acho que eu tenho uma dificuldade auditiva de discriminar a voz humana. Eu sinto que eu tenho uma dificuldade de discriminar, não é de reconhecer o som, é de discriminar o que a pessoa está falando. Nossa, tem pessoas cegas que eu fico impressionada, ficam anos sem encontrar uma pessoa e quando encontra diz: 'Fulano'. Eu não sou capaz de fazer isso, eu nunca tenho certeza de quem é que está falando, eu tenho essa dificuldade. [Ao mesmo tempo] Eu também estou muito treinada a ficar muito ligada no barulho, né, porque pelos sons eu descubro o que está acontecendo no mundo, em volta de mim, é como eu tenho possibilidade de ter algum controle do ambiente. Então é uma coisa que até por uma questão de sobrevivência tem que ficar ligada."

O limite é tênue e a questão parece girar em torno de onde traçar a linha entre natureza e cultura. O que nos interessa não é tanto uma participação nessa polaridade traçando a linha um pouco mais à esquerda ou à direita, mas o borrão, a emergência do opaco. Nos relatos de situações vivenciadas por pessoas cegas ou na observação a partir de ocasiões de interação, determinar se a percepção que desenvolvem é a de um corpo social ou de um corpo biológico é uma disputa que não corresponde aos múltiplos modos de ouvir de pessoas cegas. Eles emergem entrelaçados em práticas e conhecimentos locais e situados. Ao se polarizar a discussão corre-se o risco de abandonar a riqueza e a variabilidade dessas práticas. Elas apontam para questões que merecem ser consideradas: a indissociabilidade do que se convencionou chamar de percepção visual ou auditiva, a ampliação ou diminuição da capacidade perceptiva como resultado de foco, a visão como um sentido que distrai, as diversas formas de relação com o ambiente a partir de sua sonoridade.

\section{Questão de foco: a visão distrai}

Renata, cega congênita:

"A pessoa pode ser mais atenta, não é nem pela compensação não, é por que... por exemplo, eu sou cega, você 'tá fazendo as perguntas, mas você 
está vendo a estante, a parede, as mesas. Você pode de repente, sei lá, olhar pra janela não dá, porque a janela está muito alta, mas você pode olhar para qualquer coisa que te chame a atenção, que te distraia, aquela flor que está ali, qualquer coisa. Eu já não tenho isso para me distrair, então eu acho que isso talvez faça com que eu fique mais atenta. Mas não é uma compensação, entendeu? Não é 'todo cego é mais atento que vidente', não. As pessoas ficam, acabam ficando mais atentas, porque não têm com o que se distrair. É uma questão de foco."

\section{Olhos que escutam: surdez da cegueira?}

Pedro diz que ter ficado cego afetou os ouvidos:

"Olha só, tudo é um conjunto. Se você está enxergando, você ouve, você ouve porque está enxergando. Se você não está enxergando você não ouve. É um problema sério. Ouve, mas não os 100\%. Por exemplo, em ambiente fechado eu não consigo escutar o que a pessoa está falando, eu ouço assim 'bloubloublou', mas entender? Não estou entendendo."

\section{Ouvir o que outros veem: surdez da visão?}

Em uma ocasião, com Dora, fomos ao banheiro de um restaurante. Corredor estreito, uma cabine só. Ela entra primeiro e eu a aguardo do lado de fora. $\mathrm{Na}$ saída, ela esbarra com a bolsa no interruptor da luz e a luz se apaga. Antes mesmo que eu pudesse passar e reacender o interruptor ou pensar em explicar o ocorrido, ela mesma comenta "ih, apaguei a luz". Me pergunto como é que ela poderia saber que tinha apagado a luz, já que é cega e atualmente não tem mais a percepção de luz. Será possível que tivesse sentido que a bolsa esbarrou no interruptor? Pergunto para ela e ela me diz que escutou que o barulho do exaustor do banheiro tinha cessado, então deduziu que, se o botão fosse o mesmo, a luz também poderia ter apagado. Fico surpresa, porque eu definitivamente não tinha notado a existência de exaustor ou escutado barulho algum. Acendo novamente a luz e o exaustor volta a roncar.

\section{Corpo articulado pela cegueira: perceber as coisas pelos sons que emitem}

Camila, a partir dos treinamentos recebidos na reabilitação e da prática de prestar atenção com a audição, conta sobre a surpresa de passar a controlar movimentos do mundo a partir de sua sonoridade:

"Quando eu comecei a me dispor a andar sozinha, foi no segundo ano que eu já estava aqui, eu comecei a ficar muito mais perceptiva na minha audição, porque eu precisava muito dela... comecei a perceber que para mim ia facilitar a minha vida observar, assim, portas se abrindo, barulhos. Eu comecei a observar a porta do metrô, ruídos do metrô. Um dia a minha irmã 
estava na estação do metrô e estava falando no celular comigo, eu estava em casa. Foi incrível, ela estava falando, falando e eu falei 'olha, o metrô tá vindo aî', ela ‘não tá não', eu falei ‘tá sim', aí ela olhou 'tá vindo, meu Deus, mas como é que você fez isso?', eu falei 'o barulho'. E não foi chute não, eu ouvi do telefone celular dela. Porque eu me habituei com o barulho do metrô. Foi incrível, até eu me espantei com isso, mas foi real."

Desenvolver uma maior capacidade auditiva, ou seja, escutar mais ou melhor que outros, é entendido como diferente de ser treinado para interpretar os sons do ambiente e identificar sua origem, ou seja, reconhecer objetos e movimentos, próximos ou distantes - torneira vazando, abertura de uma porta, barulho característico da chegada do metrô, relação entre luz, exaustor e som -, para citar apenas alguns exemplos presentes nos depoimentos, de acoplamento corporal com o ambiente por sua sonoridade. O estímulo aos sentidos na reabilitação ou estimulação precoce parece direcionado para este segundo objetivo, apesar de que, nos depoimentos em que se atribui o adjetivo "aguçado" à percepção sensorial de pessoas cegas, as duas dimensões se misturam.

Autores como Hatwell (2003) e Kastrup, Rego-Monteiro e Manhães (2007) consideram que exercícios de estimulação sensorial permitiriam um novo uso da atenção mediante aprendizagem, aperfeiçoando em pessoas cegas sua capacidade de atenção aos estímulos táteis ou auditivos.

Estudos realizados com pessoas cegas nas áreas da neurociência e ciências cognitivas vêm sendo considerados uma oportunidade de conhecer mais sobre a capacidade plástica do cérebro humano. Um dos achados das últimas décadas foi o de que as mesmas áreas occipitais que facilitam processos visuais em pessoas videntes são recrutadas em pessoas cegas durante a codificação tátil e auditiva (Amedi et al. 2010; Cattaneo e Vecchi 2011).

Apesar de se referirem às mudanças que ocorrem no cérebro por efeito da plasticidade em termos de inputs e processamento de informações, e de considerarem que as regiões cerebrais se dividem por áreas especializadas em processar determinados tipos de informações sensoriais (auditivas, táteis, visuais), cuja ativação só dependeria da entrada do input necessário, os estudos na área da neurociência que procuram medir os efeitos da plasticidade cerebral reconhecem cada vez mais o papel do "ambiente" na formação e transformação do cérebro e também a flexibilidade e a intercomunicação entre as áreas (Pascual-Leone et al. 2006; Ghazanfar e Schroeder 2006; Martuzzi et al. 2007). Ainda que sejam mantidas as oposições interno e externo, corpo e ambiente, inato e adquirido, a interdependência e a influência mútua entre os polos passam a ser cada vez mais reconhecidas. Destacam-se nos estudos realizados nesta área palavras como plasticidade, adaptabilidade, transformação, mudança, habilidade.

Os achados recentes da neurociência a respeito do fenômeno da plasticidade cerebral talvez sejam um dos pontos que mais se aproximariam de uma 
teoria incorporada da cognição, que entende o desenvolvimento cognitivo não como a capacidade do cérebro de processar informações e gerar representações mentais, mas como um processo que resulta da ação de um corpo inteiro em um ambiente (Maturana e Varela 1995; Clark e Chalmers 1998; Lenay 2006; Auvray e Myin 2009).

O que podemos pensar é que não estamos diante de um indivíduo ou uma pessoa, corpo ou aprendizado, biologia ou cultura, natureza ou sociedade, mas de uma lógica da relação, do "e" que desfaz dualismos e que constitui a multiplicidade (Deleuze e Parnet 1998); podemos considerar, como sugere Ingold (1990), que o organismo é menos uma entidade individual do que a incorporação de um processo de vida. Nesse sentido, para o autor, o ambiente não pode mais ser visto como a soma de pré-condições exógenas ou a pessoa ser vista como a soma de traços endógenos. O comportamento não é um simples efeito de causas endógenas e exógenas. Ao invés disso, ele revela um momento de um processo de desenvolvimento contínuo dentro de um campo relacional, cujo resultado é a complementaridade mútua da pessoalidade e do ambiente.

\section{UNIVERSO TÁTIL: A MEDIAÇÃO DE OBJETOS E MATERIAIS}

O atendimento de Habilidades Básicas é principalmente centrado no objetivo de estimular o tato. Por ter esse foco principal também é considerado "pré-braille". Os outros sentidos são trabalhados de forma secundária - audição, olfato. Em Habilidades Básicas são exercitados ainda conceitos corporais importantes não só para o aprendizado do braille, como para o deslocamento e a locomoção ou mesmo para as AVD, como lateralidade, coordenação motora (dupla, grossa, fina), movimento de encaixe, pinça, esquema corporal. Os atendimentos consistem basicamente em fazer coisas com materiais. Ou talvez, por meio da ação direcionada, deixar que os materiais façam coisas com os corpos.

As atividades em Habilidades Básicas são principalmente realizadas com as mãos. A sala é pequena, tem uma mesa redonda ao centro e seis cadeiras em volta. Na parede à esquerda de quem entra, prateleiras onde ficam guardados os materiais. Uma janela alta na parede oposta à porta. Na lateral direita, encostada à parede, uma mesa retangular com algumas pastas e papéis das TO que usam a sala e um som portátil. Os atendimentos que acompanhei tinham em torno de três a cinco reabilitandos. A TO que realizava os atendimentos sugere que eu deveria experimentar fazer alguns exercícios com os olhos fechados, antes mesmo que eu manifeste esse interesse. Me conta que ela mesma já experimentou todos os jogos e materiais que tem na sala e diz que fará um programa para mim, começando do início para irmos desenvolvendo aos poucos. 
Ao invés de pensar no fazer como um projeto, Ingold (2013) sugere que o pensemos como um processo de crescimento. Isso significa colocar o fazedor, desde o princípio, como um participante entre um mundo de materiais ativos. Esses materiais são aquilo com que ele precisa trabalhar, e no processo de fazer ele une suas forças com eles, reunindo-os ou separando-os em pedaços, sintetizando ou destilando, em uma antecipação do que pode emergir. O autor propõe uma leitura longitudinal do fazer, como uma confluência de forças e materiais, ao invés de uma leitura lateral, como uma transposição da imagem para o objeto. Entender o fazer dessa maneira é considerá-lo como um processo de geração da forma - ou morfogenia. Significa atenuar qualquer distinção que possamos traçar entre organismo e artefato. Pois se organismos crescem, artefatos também. E se artefatos são feitos, organismos também são.

O estímulo ao tato e o desenvolvimento das habilidades a ele associadas é realizado pela mediação de vários tipos de "coisas" (Ingold 2012) e materiais como grãos, formas geométricas, miçangas, jogos diversos - de encaixe, dominós, de memória, letras do alfabeto emborrachadas, jogo da velha. Nesse processo, os materiais e as coisas trabalham com corpos em uma espécie de desenvolvimento morfogênico perceptivo.

O que interessa nesses mediadores não é apenas o seu formato, mas também suas texturas, o tamanho, a sensação que provocam ao toque. O propósito com que são utilizados nem sempre é o mesmo para o qual foram criados. Mesmo que haja uma proposta previamente colocada, não é a proposta que cria o trabalho. É o engajamento com os materiais, com as coisas, com os jogos. Jogos como dominó, por exemplo, além da função lúdica, ganham novas atribuições, como estimular a memória espacial, a discriminação tátil, além de serem classificados de acordo com o grau de dificuldade que oferecem a partir do material em que foram construídos e do design, mesmo que sua fabricação não tivesse originalmente este propósito. A TO me mostra quatro tipos de dominó, de níveis de dificuldade tátil crescente:

- Primeiro tipo - o mais fácil, peças grandes, inscrição das unidades em relevo.

- Segundo tipo - o tamanho da peça é maior que o primeiro, mas as unidades são inscritas em cavidades circulares (furos ao invés dos pontos saltados).

- Terceiro tipo - peças menores, unidades em cavidades.

- Quarto tipo - o mais difícil, peças ainda menores e do tipo vazadas, unidades em cavidades.

O propósito de jogar em grupo é a etapa final entre propostas intermediárias de atividades com as peças. Ela primeiro pede para que, tateando, percebam as peças e reconheçam as quantidades que estão marcadas em cada uma delas. 
Depois disso, ela joga com eles. Em um terceiro momento é que efetivamente se joga em grupo.

Alguns dos jogos utilizados no atendimento de Habilidades Básicas foram intencionalmente desenhados para crianças, como o jogo conhecido por "60 segundos”, mas são redimensionados e ressignificados quando incorporam esta nova função que desempenham - a de ajudar a habilitar corpos a uma nova realidade. Ingold (2013) considera que os materiais não existem na forma de objetos, como entidades estáticas com atributos diagnosticados. Ao invés disso, como substâncias - tornando-se - eles continuam ou perduram, sempre ultrapassando os destinos formais que, de um tempo a outro, foram atribuídos a eles, experimentando uma modulação contínua ao passarem por isso. Esse processo descrito por Ingold se aproxima da noção de acoplamento estrutural de Maturana e Varela (1995), que sugere que as interações entre organismo e ambiente são como perturbações recíprocas, que têm como resultado mudanças estruturais mútuas. O organismo e o meio devem ser pensados a partir dos processos que lhes dão forma.

Outros objetos e materiais cotidianos também podem desempenhar funções imprevistas originalmente. A professora de Braille, por exemplo, recomenda aos reabilitandos que identifica que precisam estimular mais o tato para suas aulas que peguem cartelas vazias de remédio e exercitem retirar a parte de alumínio que as reveste. Com isso estão treinando o movimento de pinça, para segurar a pulsão, mas também a sensibilidade dos dedos, para facilitar a leitura dos pontos. Materiais importam. A relação de pessoas e materiais na reabilitação parece mais próxima aqui da ideia de materiais não como objetos, mas como coisas, desenvolvida por Ingold (2012). O objeto, para o autor, se coloca diante de nós como um fato consumado, oferecendo suas superfícies externas e congeladas para a nossa inspeção. A coisa, por outro lado, é um lugar onde vários aconteceres se entrelaçam. Observar uma coisa é ser convidado para uma reunião. Na reabilitação, nas atividades propostas de reunião com as coisas, espera-se que elas ajudem a intervir em corpos, a desenvolver e moldar a percepção, a sensibilidade.

Descrevo algumas atividades que são propostas no atendimento de Habilidades Básicas e posteriormente levanto algumas questões corporificadas pela mediação tátil de texturas e materiais em atividades que realizei de olhos vendados.

\section{Atividades com mediação de missangas}

A TO entrega para a reabilitanda uma miçanga de formato, textura e tamanho específico e pede para que procure, em uma travessa cheia de miçangas e contas de formatos variados, miçangas iguais à que recebeu inicialmente e que vá separando em outro pote conforme for encontrando. Outra atividade, que segundo a TO é das mais difíceis, são pares de pequenas miçangas de formatos 
variados - florzinha, bolinha, cubo, etc. - que se encontram misturadas em uma travessa. O reabilitando tem que ir encontrando o par de cada miçanga e separar quando achar que encontrou. A dificuldade é pelo tamanho diminuto das peças e pelos formatos, que algumas vezes são semelhantes, como florzinha e estrela, ou tipos de flores muito parecidos, o que exige uma acuidade tátil já bem desenvolvida.

\section{Jogo "60 segundos"}

Peças de encaixe com formatos variados, com aproximadamente $1 \mathrm{~cm}$ cada lua, meia-lua, estrela de quatro e de cinco pontas, quadrado, círculo, retângulo, losango, trapézio, hexágono, etc. A proposta é encaixar cada peça no buraco correspondente ao seu formato num suporte. O jogo original é pensado para a pessoa fazer em 60 segundos, caso contrário as peças pulam da base e é preciso começar de novo. Normalmente, um botão lateral, quando girado, conta o tempo. Mas ali a proposta é encaixar o maior número de peças possível ao longo do tempo de duração da aula - 50 minutos - sem a ameaça do pulo. A TO diz que este é um dos exercícios mais avançados. Quando o reabilitando consegue acertar o encaixe da maior parte das peças desse jogo considera que já é um sinal de que está preparado para seguir adiante.

\section{Jogo da memória tátil}

Formas esculpidas em células quadradas de madeira, feitas de reentrâncias ou desníveis redondos ou pontudos, que apontam em diferentes direções. Todas têm pares e na proposta feita pela TO o reabilitando tem que encontrar o par de cada uma. Trabalha a percepção tátil, a coordenação motora fina e a memória tátil. $^{3}$

\section{Questões vivenciadas corporalmente: a falta de um vocabulário tátil}

$\mathrm{Na}$ primeira atividade que realizei com a venda, a TO pediu para que tocasse em partes de quatro quadrados relativamente grandes (deviam ter entre $8 \mathrm{~cm}$ e $10 \mathrm{~cm}$ de lado cada um) que estavam espalhados à frente, sentisse as diferenças e as descrevesse para ela. Cada quadrado se dividia em duas partes, que encaixavam. Além de perceber as texturas, tinha que procurar a metade do encaixe correspondente a cada um e encaixá-los numa forma. Uma das texturas parecia uma lixa, a outra uma espécie de borracha, mas não era exatamente borracha, tinham relevos mais acentuados e parecia um pouco o material daqueles quadrados que se coloca no chão para um bebê engatinhar. Não lembrei o nome

3 Alguns modelos de jogos, produtos e materiais pedagógicos para a "educação inclusiva" também podem ser encontrados no catálogo de uma loja virtual que comercializa materiais para deficientes visuais. O endereço é < www.artigosespeciais.com > (acesso em 07/10/2013, última consulta em setembro de 2014). 
do material, mas suspeitava que provavelmente tivesse um nome. O terceiro quadrado era totalmente liso e me lembrou o liso de um ladrilho, apesar de não ser feito do mesmo material, porque não tinha o peso ou consistência de um ladrilho. Procuro, mas não consigo encontrar palavras exatas para designar as coisas que toco. Começo a me dar conta de uma dificuldade que se repete posteriormente, a de não saber exatamente como descrever aqueles materiais - como era difícil detalhar as diferenças entre as texturas! O quarto quadrado também lembrava uma lixa, só que mais fina, poderia ser lixa de unha, talvez? Dava para perceber as diferenças, mas era difícil caracterizá-las, explicar ou mesmo pensar em signos que pudessem expressar aquelas diferenças. Me faltava vocabulário ou talvez o costume mesmo de qualificar as coisas pela sensação tátil delas.

Essa dificuldade classificatória foi depois remetida ao que reflete Verine (2013) a respeito das representações sociais e culturais de pessoas com deficiência visual na França. $\mathrm{O}$ autor considera que na sociedade atual, a uma experiência humana maciçamente multissensorial, intermodal, e mesmo holista, correspondem representações quase exclusivamente visuais. Haveria o que o autor chama de pregnância sociocultural do visível, fenômeno próximo ao que outros autores como Jay (1988) e Belarmino (2004) chamam, respectivamente, de "oculocentrismo" e "visuocentrismo". Em trabalho de pesquisa literária com pessoas deficientes visuais, Verine se surpreende com a constatação de que essa dominância da visão repercute nos discursos das próprias pessoas cegas ou com baixa visão - seja diretamente, pela frequência dos referentes e dos tropos visuais, seja indiretamente, pela quase ausência de notações auditivas, táteis, olfativas, gustativas. Esse silêncio sobre sensações não visuais é considerado pelo autor como uma obnubilação pelo visível.

A hipótese levantada por Verine é que o não dito estaria ligado a uma ausência - na formação discursiva tiflográfica (a escrita em relevo) e no interdiscurso dominante - de modelos textuais socialmente valorizados para a expressão das percepções e das representações não visuais. Existiria um círculo vicioso entre a pregnância do olhar nas práticas e nos discursos valorizados e a dificuldade das pessoas, cegas e não cegas, em falar sobre suas experiências não visuais. Cada um, à sua maneira, se silencia sobre as alternativas à visão: ora remetendo o perceptível e o percebido a equivalentes visuais ou a abstrações, ora inferiorizando ou depreciando os outros sentidos.

\section{Alguns efeitos da concentração tátil: acuidade, ambiente sonoro, cansaço}

Experimentação do jogo de memória tátil. Algumas peças de madeira tinham relevos em formato de ondulações, outras de cortes mais afiados, outras em formato mais achatado - retangular. Era difícil perceber, porque uma mesma peça às vezes misturava reentrâncias com essas características. Notei diferenças de: 
- profundidade dos cortes na madeira;

- distância maior ou menor entre um relevo e outro;

- formato do relevo - se pontiagudo, arrendondado, retangular;

- número de reentrâncias;

- direção dos relevos - se pontiagudos em diagonal, para qual lado, ou retos.

No princípio fui agrupando as peças que me pareciam iguais, com uma leve sensação de facilidade. À medida que foram restando menos peças, comecei a reparar mais cuidadosamente nas diferenças entre elas e percebi que não tinha sido nada detalhista no começo e deveria ter agrupado erroneamente várias peças. Quanto mais me dava conta da real dificuldade do exercício, mais exigia minha atenção e eu já não acompanhava a conversa da TO com outros dois reabilitandos que estavam na sala. No início participei um pouco da conversa, respondendo a perguntas sobre quem eu era e o que fazia ali. Aos poucos fui sentindo necessidade de me concentrar mais no que estava fazendo e automaticamente fui não só ficando mais calada, como abolindo o ambiente sonoro. Já nem distinguia mais o que eles estavam falando, o conteúdo da conversa, ouvia apenas como um barulho, um ruído de fundo que inclusive atrapalhava a concentração.

Percebi que tinha peças sobrando e que algumas eu tinha pareado sem ter certeza que eram pares e, nesse momento, começo a desconfiar que poderiam não ser. Comento com a TO e ela confirma a sensação me devolvendo três pares e dizendo para observar aquelas peças novamente. Nesse momento começo a experimentar certa angústia ao tocar nas peças e achá-las todas iguais. Não conseguia mais perceber as diferenças. Comecei a levantar a possibilidade de ter errado todas as anteriores. Noto que algumas peças tinham diferenças muito difíceis de perceber ou de ter certeza se eram realmente diferentes das outras. A dúvida se instala e sinto que não consigo identificar par nenhum mais. Uma pausa com respiração profunda ajuda a recuperar a calma. Recomeço a avaliar as peças, vagarosamente. Às vezes a diferença estava na mudança de direção de uma das reentrâncias agudas do relevo de uma peça, ou então apenas uma das reentrâncias que era arredondada. Algo muito sutil e muito flutuante, não sentia total confiança em nenhuma das decisões de pares formados dali para a frente, tinha que me certificar diversas vezes para definir que agruparia realmente aquelas duas.

Depois que revi aqueles pares e praticamente todos os outros que tinha feito antes, a TO volta ainda com mais três pares para que, mais uma vez, revisasse. Reagrupei tentando perceber as minúcias daquelas peças, colocando a unha entre cada reentrância, depois tentando pegar na peça como um todo, observando a distância entre um relevo e outro. Por fim a TO me diz para retirar a venda e me mostra quais eram as peças que estavam me confundindo 
mais. Saio de lá exausta pelo esforço da atenção, do foco, da concentração mental naquela tarefa.

Seguir o insight semiótico, como esclarece Law (1999) a respeito da teoria ator-rede, é priorizar o caráter relacional das entidades, a noção de que estas entidades são produzidas em relações, o que se aplica inelutavelmente a todos os materiais. As entidades alcançam suas formas como consequência das relações nas quais estão localizadas. São performadas por, através, dentro dessas relações. As divisões, sujeito e objeto, natureza e cultura, são efeitos, consequências, não estão previamente dadas na ordem das coisas. ${ }^{4}$

Uma das propriedades levantadas por Deleuze (1991) sobre o barroco nos ajuda a entender a sensação tátil das peças de madeira no jogo da memória tátil: a maneira pela qual as dobras de uma matéria constituem a sua textura - textura que se define menos pelas suas partes heterogêneas e realmente distintas do que pela forma como essas partes se tornam inseparáveis em virtude de dobras particulares. Os fragmentos somados das peças não constituem uma totalidade unificada, mas talvez a totalidade "ao lado" de que nos fala Deleuze. No jogo da memória tátil, encontrar a unidade de cada peça é encontrar uma totalidade ao lado das suas partes, uma unidade que não as unifica, e que se lhes junta como uma nova parte. O todo de um objeto percebido tatilmente, produzido como uma parte ao lado das partes, quando se aplica sobre elas instaura unidades transversais entre elementos que conservam toda a sua diferença nas suas dimensões próprias.

\section{HABILIDADES INCORPORADAS NAS PRÁTICAS COTIDIANAS}

As características táteis de objetos e materiais, desenvolvidas no atendimento de Habilidades Básicas, posteriormente reaparecem em práticas de classificação e ordenamento na vida cotidiana. Privilegiarei aqui uma dessas práticas para dar uma ideia das categorias envolvidas na organização e desenvolvimento desse conhecimento prático (Pols 2010). Tal conhecimento surge entremeado no dia a dia de pessoas com cegueira a partir de necessidades ou situações específicas, efêmeras, corriqueiras, localizadas. São temas que reaparecem em momentos da reabilitação, em algumas entrevistas, em situações transitórias de campo.

4 Kastrup e Tsallis (2009) fazem uma aproximação das obras de Varela e Latour que indica uma ressignificação da ideia de relação. Tanto Varela nas ciências da cognição quanto Latour nos estudos sobre a ciência deslocam a noção de relação, entendida previamente como ligação entre dois polos preexistentes, em favor de noções como acoplamento estrutural, rede e vínculo. Estas últimas possibilitariam pensar processos de invenção da cognição e de mundo. 


\section{Com que roupa?}

Escolher uma roupa nova para comprar em uma loja. Sozinho? Acompanhado? Como escolhe? Selecionar diariamente as peças de roupa que irá vestir. Organizar o guarda-roupa.

A TO, quando estava passando pela atividade do guarda-roupa em AVD, conta que uma conhecida sua tem uma irmã que é cega e que manda uma costureira marcar todas as peças de roupa com uma descrição em bordado - com um V de vermelho, se for vermelha, por exemplo. Diz que ela acha isso "fora da realidade". Bordar a cor e a condição da roupa não faz parte da condição financeira da maioria do público do IBC. Ela, como profissional de TO, não aconselha fazer isso. Acha que é muito mais proveitoso se a pessoa procurar detalhar a roupa: trabalha a memória, a destreza, a atenção. Seria muito mais funcional para a pessoa do que mandar bordar. Sugere que os reabilitandos tirem as suas roupas do armário, coloquem na frente e estudem, conheçam os detalhes para decorar, separar e organizar o armário. Apenas quando, por acaso, a pessoa gostou tanto de uma blusa que comprou duas iguais, aí sim diz para fazer uma marcação para diferenciar, mas só quando tem duas iguaizinhas.

Note-se que o adjetivo "igual" no caso mencionado acima se refere a um atravessamento de características táteis e visuais. Sendo do mesmo modelo - idêntico ao toque - não seria possível discernir também a cor específica. A marcação seria então para diferenciar o aspecto exclusivamente visual da cor. Quando essa identificação completa entre duas peças não acontece, as mais diversas características táteis das próprias peças servem como referencial para as suas cores. Camila explica: "eu vou vendo os detalhes da roupa, essa aqui eu sei que é preta, porque tem esse bordado. A outra eu sei que é clarinha, porque tem um botão e tem um negócio aqui do lado, aí é jeans clarinho... aí eu vou sabendo as coisas". Renata acrescenta novas distinções táteis para as roupas: "às vezes uma tem uma etiqueta a outra não tem, ou uma tem uma alça mais virada do que a outra, ou uma tem uma plaquinha e a outra não tem..." E Caetano diz que identifica cor e modelo das suas camisas por atributos tais como costura, detalhe na manga, abertura na lateral.

Durante o atendimento, a TO dá dicas para uma reabilitanda sobre organização de armário e identificação das roupas:

- Posição do cabide - gancho com a ponta voltada para dentro, fica mais fácil de tirar e botar.

- Organizar a roupa por ordem de tamanho. Paletó primeiro, mais perto da parede do armário, depois camisa de manga comprida, manga curta, calças. Na parte feminina - vestidos longos primeiro, vestidos curtos, saias. Sempre do maior para o menor. Vai diminuindo.

- Decorar as roupas pelos detalhes - tipo de tecido, símbolos emborrachados, corte da gola, etc. 
Camila diz que criou suas próprias estratégias de arrumação do armário depois que perdeu a visão. Entre elas, uma organização das roupas de acordo com o material dos cabides - se de plástico ou de madeira. Ou então pendura alguma coisa diferente no cabide - um cordão, um barbante, um colar - para identificar, entre dois vestidos semelhantes, que o estampado é aquele que está com cordão pendurado. Segundo ela: "Tudo tem saída. Por isso que a gente tem que ter o tempo e ter uma memória boa, estar sempre memorizando aquilo". Dora desenhou ela mesma o seu closet e desenvolveu uma gaveta com 15 subdivisões internas para arrumar coisas menores, peças íntimas, bijuterias.

Beatriz vai me mostrando o seu armário e diz que é mais bagunça do que organização, igual a qualquer outro. Não faz marcação na roupa e evita comprar peças iguais. Vai tocando nas roupas, reconhecendo quais são e me descrevendo - "Essa aqui é preta, cheia de coisinha dourada, essa é uma jaqueta jeans, essa meio amarrotadinha é listadinha de preta com verde, essa outra eu sei que é estampada, aquela é azul". Mas diz que às vezes erra, acha que é uma coisa, mas é outra. Para ela é suficiente saber se é estampada ou se é lisa e azul. Na hora que compra sempre pergunta exatamente como é, mas esquece depois. Lembra se é ou não estampada, mas com o tipo exato de estampa não se importa tanto. De vez em quando, no trabalho, pergunta para alguém "Gente, que cor é essa blusa mesmo, hein?"

A necessidade de ajuda de outra pessoa para comprar ou escolher roupa vai variar de acordo com a situação e o propósito. Quando necessária, a ajuda não é indeterminada, não é uma questão de quantificar se a pessoa precisa de mais ou menos (Struhkamp, Mol e Swierstra 2009). Para cada um, importa muito, por exemplo, quem é a pessoa que está ajudando - se conhecida ou desconhecida, se confia e como confia, vendedor de loja, parente ou amigo, se tem a personalidade mais antiquada ou mais "moderna". Faz diferença estar acompanhado de uma ou de duas pessoas. Cada um parece criar suas próprias estratégias na hora de escolher a roupa que quer comprar em uma loja. Dentre os critérios que participam na seleção de uma boa ou má combinação, não é necessariamente o visual que predomina ou que vai determinar se a aparência de uma roupa é bonita ou feia, agradável ou desagradável.

Ao longo das conversas, pelos próprios exemplos que os pesquisados vão me mostrando na hora, pelas histórias que vão lembrando, vai aparecendo uma estética tátil, que nem sempre condiz com critérios de beleza estritamente visuais, e outras vezes mesmo contradiz. Ana gosta de tecido de laise, um tecido leve de algodão, com aplicação de bordados, que pode ser vazado. Ou então gosta de tecidos com bolinhas, que tenha uns babadinhos. Segundo ela não é nada que chame a atenção, não é nada enorme, gosta de roupa suave. Mas com alguma aplicação de miçanga, uma textura, um broche ou então umas pedrinhas. Algum enfeite. Pela estética, acha bonito. A blusa pode até ser lisa, mas que tenha algum lacinho, algum detalhe. 
Já Dora gosta de inventar as combinações das suas roupas - cores, bijuterias, aspectos táteis. Tem dias em que está mais alegre, mais ousada, que está com vontade de misturar. Descobre se a sua ousadia saiu ou não do jeito que queria pelos comentários das pessoas. Mas se fica em dúvida e quer saber antes de usar, pergunta para alguém. Esse alguém, entretanto, não pode ser qualquer um. Geralmente pergunta para mais de uma pessoa e de acordo com o que chama de "estilo" ou "personalidade" dela. Algumas pessoas são mais rígidas, só vão falar que está combinando quando estiver muito "em cima". Outras são mais tolerantes, têm uma gama maior para poder combinar. Algumas preferem combinações mais modernas, determinadas pessoas vão ficar naquelas mais antigas... E se tem aqueles dias em que está todo mundo vestido de uma mesma cor no trabalho ou num encontro social, ela geralmente está nesse grupo.

Um dia Ana, se vestindo com pressa, pegou uma blusa e uma calça cujas cores sabia que combinavam, digamos que fossem azul e branco, não lembrava mais. Mas alguma coisa lhe pareceu estranha: o tecido da blusa não estava combinando com o tecido da calça. Disse que ninguém repara nisso, ninguém falou nada o dia todo, mas para ela tem tecidos que combinam e outros que não, e naquele dia não estavam combinando. Ninguém vai a uma festa e bota uma calça de malha e uma blusa "linda, toda social". A cor pode até combinar, mas o tecido não. "Já imaginou você pegar uma blusa assim de seda e botar com uma calça de malha? Fica esquisito".

Dora foi pegar um exemplo vivo de um efeito que estava me explicando: quando visualmente algo tem uma aparência, mas que no tato é outra. Voltou com uma saboneteira. "O pessoal diz que essa saboneteira, quando é novinha, não parece que é de plástico, parece que ela quebra, que é de vidro, entendeu?" A saboneteira é o exemplo de algo que visualmente é uma coisa, mas que no tato jamais daria a impressão de que pudesse ser algo semelhante a vidro. Mesmo que dissessem que é toda transparente ela nunca acharia, pegando, que visualmente parece vidro para ninguém, nem para os mais distraídos. $\mathrm{O}$ mesmo "efeito saboneteira" acontece com as pessoas e com muitas outras coisas que visualmente dão uma aparência e no tato têm outra. Às vezes acontecia de implicar com alguma peça sua pelo tato, achar que não estava legal e as pessoas dizerem que visualmente estava - uma roupa, uma bijuteria, uma caixinha de guardar, qualquer coisa assim. Aí lembra que antigamente ficava se obrigando a achar que estava legal só porque visualmente diziam que estava. De uns tempos para cá se libertou: "Não, peraí, mas quem manda aqui sou eu!" Se o tato não está legal, não quer saber se visualmente está legal, problema de quem vê. Se para ela não está, não quer, não usa e acabou. Quando é ao contrário, o tato está legal, mas as pessoas dizem "Olha, está desbotada, não ficou bom", ela também não usa. Então, quando no tato não está legal, visualmente pode estar ótimo para quem quiser; para ela, não. 


\section{CONSIDERAÇÕES FINAIS}

Aprender a utilizar uma nova realidade corporal, a que não enxerga, para perceber proporções diversas para as coisas e saber empregá-las. Incorporação de novos jeitos, novas habilidades, no desempenho de tarefas conhecidas - colocar água num corpo, fazer comida, organizar o armário, escolher a roupa.

O processo por meio do qual uma pessoa é composta é chamado processo de habilitação. Como lembra Winance (2006), o processo de habilitação é o processo pelo qual não apenas a ação, mas uma pessoa (d)eficiente emerge. Ela adquire capacidades, mas também incapacidades, por meio da transformação de quem ela é, do que o seu corpo é, do que o seu mundo é. Neste artigo buscou-se apresentar a natureza e o tipo de trabalho que pessoas com cegueira e o seu coletivo (humano e não humano) produzem para fabricarem a si próprias como pessoas capazes. Acredita-se que uma análise desse tipo possa contribuir para compreender tanto as suas semelhanças quanto as suas diferenças, procurando aproximar as diferenças do múltiplo e não do diverso.

Por meio do engajamento corporal com materiais na reabilitação, nos acoplamentos que se cria com eles, os materiais ajudam a criar um novo corpo, ao mesmo tempo em que são recriados nesse vínculo. A miçanga não é mais uma conta para fazer um colar ou pulseira. Ela escapa, excede. Características de vários conjuntos de peças de dominó são descobertas e reclassificadas, de acordo com o que provocam no engajamento tátil com elas. Se engajar, fruir, interagir, se misturar com materiais para que eles possam atuar no corpo, promover uma espécie de abertura perceptiva e modificá-lo.

O fazer de reabilitandos com jogos, coisas e materiais na reabilitação está próximo à ideia de invenção de novos vínculos, aprendizagem de ser afetado ou o processo de adquirir um corpo, num paralelo que pode ser feito com a maleta de odores desvendada por Latour (2004), onde a maleta e o corpo são transformados no processo de criação de um "nariz". Na prática de treinamento de "narizes" para a indústria de perfumes, um nariz "mudo", após uma semana de treinamento onde o instrutor e o kit de odores (a maleta) desempenham um papel fundamental, passa a ser capaz de discriminar um número crescente de diferenças sutis que antes não podia perceber - aprende-se a ter um nariz que permite habitar um mundo olfativo amplamente diferenciado. A mudança não é apenas da desatenção para a atenção, mas um aprendizado de ser afetado, efetuado pela influência dos materiais - no caso que analisamos, ao ser posto em ação por esses materiais. Aprendizagem que se dá pelo corpo.

Para Latour esse é um processo de articulação contextualizado, local. O termo articulação enfatiza a necessidade de trazer à tona os componentes artificiais e materiais que permitem, gradativamente, adquirir um corpo. Outra característica dessa ideia de articulação é a possibilidade de sua proliferação, sendo absolutamente desnecessária a correspondência. Não se espera que os relatos dos sujeitos articulados convirjam numa versão única, apenas 
que sejam articulados pelo kit (dominós, miçangas, texturas, etc.). Ser capaz de ser afetado por mais e mais diferenças, que, posteriormente, auxiliarão na categorização e organização do mundo nas práticas cotidianas.

A proposta inicial nos atendimentos de Habilidades Básicas é de que se articulem movimentos e gestos aos jogos e materiais que ali são apresentados, mas, depois, as marcas desses acoplamentos e articulações são levadas para a própria vida. Seguir o fluxo e as forças dos materiais que conduzem a outras formas de fazer e de perceber, à fruição. Corpos que são feitos pelos materiais. Materiais que ressurgem como efeitos dessas outras formas de aproximá-los. Desenvolvimento de um histórico de novos acoplamentos estruturais com o meio, a fim de reinventar a existência.

É preciso lembrar que esses mediadores são principalmente pensados, desenvolvidos ou utilizados com o fim de "habilitar" a cegueira em um mundo visual, mas parecem atuar em uma única direção. Necessário ainda, se quisermos seguir um caminho de simetrização sugerido pelo coletivo AbaEté, ${ }^{5}$ multiplicarmos formas de nos deixar - a nós videntes, majoritários - habilitar pela não visão minoritária, pelos seus conhecimentos e suas práticas incorporadas, a fim de multiplicar espaços de contato, desestabilizar modelos dominantes, criar afetos.

\section{BIBLIOGRAFIA}

AMEDI, A., et al., 2010, "Cortical activity during tactile exploration of objects in blind and sighted humans”, Restorative Neurology Neuroscience, 28 (2): 143-156.

AUVRAY, Malika, e Erik MYIN, 2009, "Perception with compensatory devices: from sensory substitution to sensoriomotor extension”, Cognitive Science, 33 (6): 1036-1058.

Belarmino, Joana, 2004, Aspectos Comunicativos da Percepção Tátil: A Escrita em Relevo como Mecanismo Semiótico da Cultura. São Paulo, Pontifícia Universidade Católica de São Paulo (PUC-SP), tese de doutorado.

Bourdieu, Pierre, 201 1, O Senso Prático. Petrópolis, Vozes.

CATTANEO, Zaira, e Tomaso VECCHI, 201 1, Blind Vision: The Neuroscience of Visual Impairment. Londres, The MIT Press.

CLARK, Andy, e David CHALMERS, 1998, “The extended mind”, Analysis, 58 (1): 7-19.

DELEUZE, Gilles, 1991, A Dobra: Leibniz e o Barroco. Campinas, Papirus.

5 Texto "Simetria, reversibilidade, reflexividade", que se encontra no site $<$ https://sites.google.com/ a/abaetenet.net/nansi/Home/simetria-reversibilidade-e-reflexividade > (acesso em 17/10/2013, última consulta em setembro de 2014). 
DEleuZE, Gilles, e Claire PARNET, 1998, Diálogos. São Paulo, Escuta.

GHAZANFAR, Asif A., e Charles E. SCHROEDER, 2006, "Is neocortex essentially multisensory?", Trends in Cognitive Sciences, 10 (6): 278-285.

GIBSON, James J., 1979, The Ecological Approach to Visual Perception. Boston, Houghton Mifflin.

HATWELl, Yvette, 2003, Psychologie cognitive de la cécité précoce. Paris, Dunod.

INGOLD, Tim, 1990, "An anthropologist looks at biology", Man, n. s., 25 (2): 208-229.

INGOLD, Tim, 2012, "Trazendo as coisas de volta à vida", Horizontes Antropológicos, 37: 25-44.

INGOLD, Tim, 2013, Making: Anthropology, Archaeology, Art and Architecture. Londres, Routledge.

JAY, Martin, 1988, “Scopic regimes of modernity”, em H. Foster (org.), Vision and Visuality: Discussions in Contemporary Culture (2). Seattle, Bay Press, 3-27.

KASTRUP, Virgínia, Paula REGO-MONTEIRO, e Luciana P. MANHÃES, 2007, "Questões acerca da teoria da compensação no campo da deficiência visual", Revista do Instituto Benjamin Constant, 36 (13): 22-27.

KASTRUP, Virgínia, e Alexandra TSALLIS, 2009, "Acoplamentos, vínculos e deficiência visual: sobre um vetor de atravessamento Varela-Latour", Informática na Educação: Teoria \& Prática, 12 (2): 12-22.

LATOUR, Bruno, 1996, "On interobjectivity", Mind, Culture and Activity, 3 (4): 228-245.

LATOUR, Bruno, 1999, "On recalling ANT", em John Law e John Hassard (orgs.), Actor Network Theory and After. Oxford, Blackwell Publishers, 15-25.

LATOUR, Bruno, 2004, "How to talk about the body? The normative dimension of science studies", Body \& Society, 10 (2): 205-229.

LAW, John, 1999, "After ANT: complexity, naming and topology", em John Law e John Hassard (orgs.), Actor Network Theory and After. Oxford, Blackwell Publishers, 1-14.

LENAY, Charles, 2006, "Enaction, externalisme et suppléance perceptive", Intellectica, 43: 27-52.

MARTUZZI, Roberto, et al., 2007, "Multisensory interactions within human primary cortices revealed by BOLD dynamics”, Cerebral Cortex, 17 (7): 1672-1679.

maturanA, Humberto, e Francisco VARElA, 1995, A Árvore do Conhecimento. Campinas, Editorial Psy.

PASCUAL-LEONE, A., et al., 2006, "The role of visual cortex in tactile processing: a metamodal brain”, em M.A. Heller e S. Ballesteros (orgs.), Touch and Blindness: Psychology and Neuroscience. Mahwah, NJ, Lawrence Erlbaum, 171-195.

POLS, Jeannette, 2010, "Bringing bodies - and health care - back in", Medische Antropologie, 22 (2): 413-427.

STRUHKAMP, Rita, Annemarie MOL, e Tsjalling SWIERSTRA, 2009, “Dealing with in/dependence: doctoring in physical rehabilitation practice", Science, Technology \& Human Values, 34 (1): 55-76.

VARELA, Francisco, 2003, “O reencantamento do concreto", Cadernos de Subjetividade, 1 ( 1): 71-86.

VERINE, Bertrand, 2013, "Não podemos ver, não devemos tocar: quais as repercussões dessa máxima no discurso das pessoas cegas?”, Revista Benjamin Constant, 19: 6-19.

WINANCE, Myriam, 2006, "Trying out the weheelchair: the mutual shaping of people and devices through adjustment”, Science, Technology \& Human Values, 31 (1): 52-72. 